\title{
The Effect of Asparagine on the Growth of a Gram-Positive Coccus
}

\author{
By ELLEN I. GARVIE, MARGARET E. GREGORY AND L. A. MABBITT \\ National Institute for Research in Dairying, Shinfield, Reading
}

(Received 31 May 1960)

\section{SUMMARY}

A Pediococcus sp., unusual in that it needed reducing conditions for growth, would not grow in a medium based on acid-hydrolysed casein but grew when asparagine was added. Neither glutamine nor aspartic acid + an ammonium salt satisfied this requirement. When the acid-hydrolysed casein was replaced by a mixture of amino acids, the omission of asparagine caused a decrease in growth in the presence of aspartic acidtan ammonium salt. No growth occurred in the absence of both aspartic acid and asparagine.

\section{INTRODUCTION}

Strains of Gram-positive cocci morphologically similar to Pediococcus cerevisiae but differing in other respects were described by Gunther (1958). Since a requirement for folinic acid may be a useful character for recognizing the pediococci (Felton \& Niven, 1953), an attempt was made to determine this requirement for some of Gunther's strains. This was done in a casein hydrolysate medium based on that described by Sauberlich \& Baumann (1948) for the assay of folinic acid with $P$. cerevisiae ATCC 8081. However, none of these strains grew in this medium even when folinic acid was present, although a normal response to this growth factor was given by the assay organism. It was found that growth occurred when Tween 80 and tryptic digest of casein were added to the medium (Garvie \& Gregory, to be published). Therefore, a search to identify the active component in the tryptic digest was undertaken.

\section{METHODS}

Test organism and its maintenance. Strain NCDO 1250, sent by Dr H. L. I. Gunther under the reference number S344, was used. It is a catalase-negative Gram-positive coccus, growing in pairs, tetrads and clusters but not in chains, and is considered to belong to the genus Pediococcus. It differs from other known strains of this genus in being unable to grow aerobically in normal media. It was grown anaerobically in a McIntosh \& Fildes jar filled with $90 \%(v / v) \mathrm{H}_{2}+10 \%(v / v) \mathrm{CO}_{2}$ or alternatively in the presence of air by adding $0.5 \mathrm{ml}$. of a $1 \%(\mathrm{w} / \mathrm{v})$ Seitz-filtered solution of cysteine hydrochloride or ascorbic acid to each $10 \mathrm{ml}$. of medium immediately before inoculation.

The strain was maintained in litmus milk supplemented with $0.3 \%(w / v)$ Yeastrel, $1 \%(w / v)$ glucose, $0 \cdot 1 \%(v / v)$ Tween $80,1 \%(w / v)$ chalk; cysteine hydrochloride 
was added aseptically. After incubation at $30^{\circ}$ for $24 \mathrm{hr}$. the cultures were stored at $4^{\circ}$.

Preparation of inoculum. The strain was grown in tomato glucose broth medium (Briggs, 1953) modified by Dr M. E. Sharpe, and having the following composition: $(\%, \mathrm{w} / \mathrm{v}) 1 \cdot 5$, peptone (Oxoid); $2 \cdot 0$, glucose; 0.5 , Yeastrel; 0.5 , sodium acetate; $0.5, \mathrm{KH}_{2} \mathrm{PO}_{4} ; 0.2$, di-ammonium citrate; $(\%, \mathrm{v} / \mathrm{v}) \mathbf{1 0} \cdot 0$, tomato juice (Oxoid); $0 \cdot 1$, Tween $80 ; 0.5$, salts B (Snell \& Strong, 1939); adjusted to $\mathrm{pH} 6.5$ and autoclaved (15 min. at $10 \mathrm{lb} . / \mathrm{sq} . \mathrm{in}$.$) . Cysteine hydrochloride was added aseptically as described$ above. Serial transfers with an inoculum of $c .0 .01 \mathrm{ml}$. were made after incubation for $48 \mathrm{hr}$. at $30^{\circ}$. A $24 \mathrm{hr}$. culture of the $3 \mathrm{rd}-5$ th transfer was used as the inoculum for the growth tests; one drop of a 1/100 dilution in quarter strength Ringer solution was inoculated into each assay tube.

Growth tests. The basal media (Table 1), which were modifications of that of Sauberlich \& Baumann (1948), were made up at double strength and added in $5 \mathrm{ml}$. quantities to optically matched test tubes containing $5 \mathrm{ml}$. of test solution. The tubes were then covered with aluminium caps and autoclaved $(10 \mathrm{~min}$. at $10 \mathrm{lb} . / \mathrm{sq}$. in.). They were inoculated with strain NCDO 1250 and incubated at $30^{\circ}$ for $48 \mathrm{hr}$., either aerobically or anaerobically, as described above. Relative amounts of growth were estimated turbidimetrically with a Lumetron 400-A colorimeter (Photovolt Co., New York).

Amino acid requirement of strain NCDO 1250. The growth of the cultures was measured in the defined medium $\mathbf{A}$ from which the amino acids were omitted, each in turn. Since cystine was one of the amino acids under test cysteine could not be used as a reducing agent and ascorbic acid was used instead in the tests incubated in air. Cultures which grew in the first test were serially transferred in the same medium to eliminate carry over of nutrients.

Estimation of the amino acid content of acid-hydrolysed casein and Tryptone by paper chromatography. Aqueous solutions $(1 \%, \mathrm{w} / \mathrm{v})$ were adjusted to $\mathrm{pH} 2$ by adding $\mathrm{N}-\mathrm{HCl}$ and desalted on Dowex $50\left(\mathrm{H}^{+}\right)$resin columns. The desalted eluates were concentrated under reduced pressure at $50^{\circ}$ and used to prepare two-dimensional chromatograms on no. 1 Whatman paper by the procedure of Levy \& Chung (1953).

Chemical estimation of glutamine and asparagine in Tryptone. Five ml. of $1 \%(\mathrm{w} / \mathrm{v})$ aqueous Tryptone (Oxoid) was hydrolysed in $\mathrm{N}-\mathrm{HCl}$ for the estimation of total amide-N, and in borate phosphate buffer at $\mathrm{pH} 6.5$ for the estimation of the amide-N of glutamine (Vickery et al. 1935). The ammonia produced was distilled into boric acid containing a mixed indicator of bromcresol green and methyl red (Conway, 1957). Solutions of glutamine and asparagine were analysed as controls, and blank values were determined by using distilled water as the test solution.

Free amino acid content of strain NCDO 1250. The strain was grown in the defined medium $\mathbf{A}$ as described earlier but with $(a)$ asparagine omitted, $(b)$ aspartic acid omitted, (c) asparagine and aspartic acid omitted but with Tryptone (Oxoid $5 \mathrm{mg} . / \mathrm{ml}$.) added. Extracts of washed organisms were made in $10 \%(\mathrm{v} / \mathrm{v})$ acetic acid and chromatograms prepared from the extracts by the method of Mattick, Cheeseman, Berridge \& Bottazzi (1956). 


\section{RESULTS}

Growth of strain NCDO 1250 in medium $A$ and medium $B$. Good growth was obtained in defined medium $A$ which contained a mixture of 19 amino acids and an ammonium salt. In contrast, growth did not occur under aerobic or anaerobic conditions in the partially defined medium $\mathbf{B}$ in which the amino acid mixture was replaced by acid-hydrolysed casein + tryptophan, cysteine, tyrosine, phenylalanine and histidine (Table 1), even in the presence of $1 \mu \mathrm{g}$. folinic acid/ml. medium. However, growth did occur under both conditions of incubation when $0.5 \%(\mathrm{w} / \mathrm{v})$ Tryptone (Oxoid; a tryptic digest of casein) was added. These observations suggested that medium $\mathbf{B}$ was deficient in some nitrogenous component and accordingly the amino acid requirements of the strain were studied.

\section{Table 1. Composition of double strength media}

\begin{tabular}{|c|c|c|c|}
\hline & Medium A & & \\
\hline Glucose & $50 \mathrm{~g}$. & DL-Alanine & $400 \mathrm{mg}$. \\
\hline Sodium acetate & $40 \mathrm{~g}$. & L-Arginine & $400 \mathrm{mg}$. \\
\hline $\mathrm{NH}_{4} \mathrm{Cl}$ & $6 \mathrm{~g}$. & L-Aspartic acid & $200 \mathrm{mg}$. \\
\hline Salts A (Snell \& Strong, 1939) & $12 \mathrm{ml}$. & L-Asparagine & $800 \mathrm{mg}$. \\
\hline Salts B (Snell \& Strong, 1939) & $10 \mathrm{ml}$. & L-Cystine & $100 \mathrm{mg}$. \\
\hline Tween 80 & $2 \mathrm{ml}$. & L-Glutamic acid & $600 \mathrm{mg}$. \\
\hline Adenine, guanine, uracil, xanthine, each & $20 \mathrm{mg}$. & Glycine & $200 \mathrm{mg}$. \\
\hline Thiamine hydrochloride & $1000 \mu \mathrm{g}$ & L-Histidine & $100 \mathrm{mg}$. \\
\hline $\begin{array}{l}\text { Pyridoxal ethyl acetal } \\
\text { hydrochloride }\end{array}$ & $2000 \mu \mathrm{g}$ & $\begin{array}{l}\text { DL-Isoleucine } \\
\text { DL-Leucine }\end{array}$ & $\begin{array}{l}500 \mathrm{mg} . \\
500 \mathrm{mg} .\end{array}$ \\
\hline Ca-D-pantothenate & $1000 \mu \mathrm{g}$ & L-Lysine & $400 \mathrm{mg}$. \\
\hline Riboflavin & $1000 \mu \mathrm{g}$ & DL-Methionine & $200 \mathrm{mg}$. \\
\hline Nicotinic acid & $2000 \mu \mathrm{g}$ & DL-Phenylalanine & $200 \mathrm{mg}$. \\
\hline$p$-Aminobenzoic acid & $200 \mu \mathrm{g}$ & L-Proline & $200 \mathrm{mg}$. \\
\hline Biotin & $2 \mu \mathrm{g}$. & DL-Serine & $100 \mathrm{mg}$ \\
\hline Folic acid & $20 \mu \mathrm{g}$. & $\begin{array}{l}\text { DL-Threonine } \\
\text { DL-Tryptophan } \\
\text { L-Tyrosine } \\
\text { DL-Valine }\end{array}$ & $\begin{array}{l}400 \mathrm{mg} \text {. } \\
80 \mathrm{mg} \text {. } \\
200 \mathrm{mg} \text {. } \\
500 \mathrm{mg} \text {. }\end{array}$ \\
\hline
\end{tabular}

Volume to $1000 \mathrm{ml}$. $\quad \mathrm{pH} \mathrm{6 \cdot 8.}$

Medium B

Medium $B$ had the same composition as medium $A$ except that $10 \mathrm{~g}$. vitamin-free acid hydrolysed casein (Difco or Allen and Hanbury's), $80 \mathrm{mg}$. tryptophan, $200 \mathrm{mg}$. cystine and $400 \mathrm{mg}$. each tyrosine, phenylalanine and histidine were used in place of the amino acid mixture.

Amino acid requirement of strain NCDO 1250. Omission of the following amino acids (singly) from medium A prevented growth of strain NCDO 1250: arginine, cystine, glutamic acid, glycine, histidine, isoleucine, leucine, methionine, phenylalanine, proline, serine, threonine, tryptophan, tyrosine, valine. In contrast, no effect on growth was observed when alanine, aspartic acid or lysine was omitted. The omission of asparagine, however, decreased growth by some $50 \%$.

The amino acid deficiency of medium $B$. Chromatograms prepared from the Allen and Hanbury's acid-hydrolysed casein indicated that, as compared with medium $\mathbf{A}$, medium $\mathbf{B}$ was deficient only in methionine and asparagine. The addition of either or both of these amino acids showed that asparagine was the limiting growth factor. In contrast, chromatograms of Tryptone showed the presence 
of asparagine. By chemical analysis $1 \mathrm{mg}$. Tryptone was found to contain $0.08 \mathrm{mg}$. asparagine and a negligible amount of glutamine. In medium $B$ the growth responses to Tryptone and asparagine were similar (Fig. 1 ) and indicated that $1 \mathrm{mg}$. Tryptone was equivalent in activity to about $0.15 \mathrm{mg}$. asparagine.

Specificity of the requirement of strain NCDO 1250 for asparagine. The growth activity of asparagine in medium $B$ was not replaced by aspartic acid at 25-200 $\mu \mathrm{g}$./ $\mathrm{ml}$. or by glutamine (1-500 $\mu \mathrm{g} / \mathrm{ml}$.) or glutathione (1-500 $\mu \mathrm{g}$. $/ \mathrm{ml}$.). In the absence

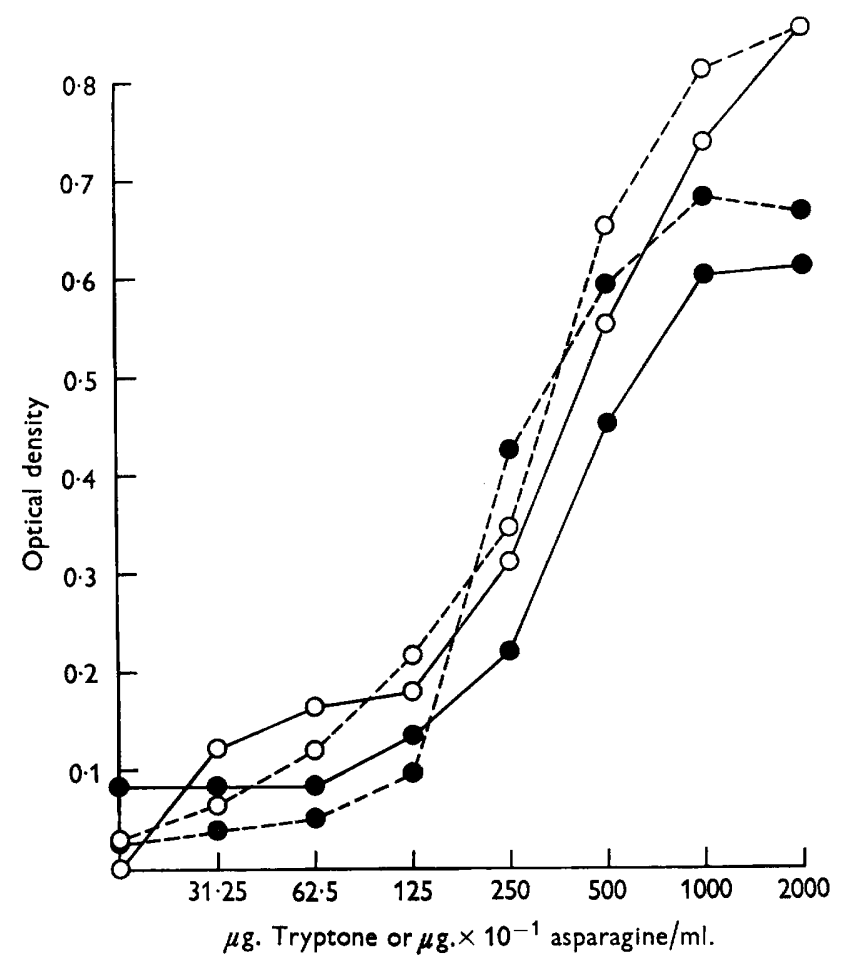

Fig. 1. Growth response of Pediococcus NCDO 1250 to Tryptone or asparagine after $48 \mathrm{hr}$. in medium $\mathrm{B}$ at $30^{\circ}$. $-1=$ +asparagine aerobically with ascorbic acid; $0---O=+$ asparagine anaerobically; $\mathrm{O}-\mathrm{O}=+$ Tryptone aerobically with ascorbic acid; $\mathrm{O}--\mathrm{O}=+$ Tryptone anaerobically.

of both asparagine and aspartic acid from the defined medium $A$ no growth occurred until either one or other of the acids was replaced. The growth response to asparagine (aspartic acid absent) was greater than that to aspartic acid (asparagine absent) at the same concentration by weight $(0.1$ or $0.4 \mathrm{mg} . / \mathrm{ml}$.). Increasing the glutamic acid up to $0.9 \mathrm{mg} . / \mathrm{ml}$. had no effect on growth.

Effect of asparagine on the amino acid pool. The amino acids found in the extracts of organisms grown in the defined medium $\mathbf{A}$ when either asparagine or aspartic acid was omitted, or with both omitted and tryptone added, were qualitatively and quantitatively similar. There were two outstanding features. First, no asparagine could be detected in the organisms even when it had been added to the medium, and, secondly, even when aspartic acid was omitted from the medium, it could still be found in the organisms in undiminished concentration. 


\section{DISCUSSION}

The use of asparagine in bacteriological media is widespread. In media based on acid-hydrolysed casein it has been reported to stimulate the growth of lactobacilli (Evans \& Niven, 1951) and, together with glutamine, of Streptococcus lactis (Niven, 1944). Asparagine also promoted the growth of butyric acid bacteria in corn mash but aspartic and glutamic acids were equally effective (Tatum, Peterson \& Fred, 1935). Our finding that the Pediococcus strain NCDO 1250 in acid-hydrolysed casein medium had a requirement for asparagine which could not be replaced by glutamine or aspartic acid is similar to that of Niven (1944) for certain of his strains of Streptococcus lactis. However, when the casein hydrolysate was replaced by a mixture of amino acids the requirement of the Pediococcus for asparagine was satisfied by aspartic acid + an ammonium salt. It seemed possible that the requirement for asparagine in acid-hydrolysed casein medium was due to an imbalance of amino acids in the medium. For example, the large amount of glutamic acid in acid-hydrolysed casein might inhibit the transport of aspartic acid into the cell (Gale \& van Halteren, 1951). However, no support for this hypothesis was obtained. Growth was not promoted when the concentration of aspartic acid was increased nor did high concentrations of glutamic acid inhibit growth in the defined medium.

Stokes, Koditschek, Rickes \& Wood (1949) suggested a relationship between asparagine and strepogenin activity. In agreement with this, a major part of the stimulatory activity of Tryptone for the Pediococcus in the acid-hydrolysed casein medium could be attributed to its asparagine content. Asparagine peptides in the Tryptone would not be estimated by the procedure used and might account for the remaining activity (Miller \& Waelsch, 1952). The precise role of asparagine in the metabolism of the Pediococcus strain examined remains to be established. Examination of the amino acid pool showed that asparagine was not concentrated there, suggesting that it was rapidly metabolized to provide as one of its functions the aspartic acid requirement of the cell. Whether under certain conditions it is more effective than aspartic acid because it is more easily transported into the cell remains to be determined.

The authors wish to thank Dr H. L. I. Gunther (Queen Elizabeth College, London University) for supplying the strain used in the investigation. They also thank Dr M. E. Sharpe (National Institute for Research in Dairying) for permission to publish the recipe of the tomato glucose broth.

\section{REFERENCES}

Briggs, M. (1953). An improved medium for lactobacilli. J. Dairy Res. 20, 36.

Conway, E. J. (1957). Micro-Diffusion Analysis and Volumetric Error, p. 99. London: Crosby Lockwood and Son.

Evans, J. B. \& Niven, C. F. (1951). Nutrition of the heterofermentative lactobacilli that cause greening of cured meat products. J. Bact. 62, 599.

Felton, E. A. \& Niven, C. F. (1953). The identity of Leuconostoc citrovorum strain 8081 . J. Bact. 65, 482.

Gale, E. F. \& Van Halteren, M. B. (1951). The assimilation of amino acids by bacteria. 13. The effect of certain amino acids on the accumulation of free glutamic acid by Staphylococcus aureus: extracellular peptide formation. Biochem. J. 50, 34. 
GUNTher, H. L. I. (1958). A study of the physiological and serological characters of som pediococci. Ph.D. Thesis, University of London.

LeVy, A. L. \& Chung, D. (1953). Two-dimensional chromatography of amino acids on buffered paper. Analyt. Chem. 25, 396.

Mattick, A. T. R., Cheeseman, G. C., Berridge, N. J. \& Bottazzi, V. (1956). The differentiation of species of lactobacilli and streptococci by means of paper partition chromatography. J. appl. Bact. 19, 810.

Miller, H. K. \& WAELSCH, H. (1952). Utilization of glutamine and asparagine and their peptides by microorganisms. Nature, Lond. 169, 30.

Niven, C. F. (1944). Nutrition of Streptococcus lactis. J. Bact. 47, 343.

Sauberlich, H. E. \& Baumann, C. A. (1948). A factor required for the growth of Leuconostoc citrovorum. J. biol. Chem. 176, 165.

Snell, E. E. \& Strong, F. M. (1939). A microbiological assay for riboflavin. Ind. Engng Chem. (Anal.), 11, 346.

Stokes, J. L., Kodrtschek, L. K., Rickes, E. L. \& Wood, T. R. (1949). Factors affecting the rate of growth of Lactobacillus casei. J. biol. Chem. 178, 93.

Tatum, E. L., Peterson, W. H. \& Fred, E. B. (1935). Identification of asparagine as the substance stimulating the production of butyl alcohol by certain bacteria. J. Bact. 29, 563.

Vickery, H. B., Pucher, G. B., Clark, H. E., Chibnali, A. C. \& Westall, R. G. (1935). The determination of glutamine in the presence of asparagine. Biochem. J. 29, 2710. 